\section{A TEXTBOOK OF THE PRACTICE OF MEDICINE}

Edited by Frederick W. Price, F.R.S.Ed., M.D., C.M.Ed., F.R.C.P., Hon. M.D., 8th edition. Pp. xlv +2076 . London: Geoffrey Cumberlege, Oxford University Press. 1950. 45s.

Now containing over 2,000 pages, Price's 'Medicine' remains the most comprehensive and authoritative single-volume English textbook. Only four years have passed since the last revision, yet this edition contains 66 articles which are new or have been completely re-written. Most of the distinctive features of early editions remain; here are still the classical descriptions of the specific fevers, the brilliant and comprehensive articles on tropical diseases and the beautifully written, lucid section on diseases of the nervous system. The valuable sections devoted to endocrinology, skin diseases and psychological medicine have also been revised, so that there is no speciality in medicine not included.

Yet it must be admitted that the greater part of this edition gives less cause for satisfaction. New articles have been added, but has the dead wood been drastically cut out? Does it do justice to recent research-in particular to the excellent work done in this country since the war? Surely most of this should find some place in the standard English textbook whose sales, we are told in the preface, are almost as great abroad as at home?

Looking for references to much of this work, one is sadly disappointed. Nothing is said on the treatment of anuria. The sections on peripheral vascular disease and on venous thrombosis are quite inadequate for a modern textbook. Scant reference is made to recent work on constrictive pericarditis. 'High output' failure and its treatment are not mentioned. Ellis's classification of nephritis has been grafted on to the old one in a meaningless fashion so that the whole subject is made more confusing than ever before. It is an anachronism that 'a textbook of clinical pathology should be consulted "for the urea clearance test," while the urea concentration test, which nobody uses, is described in detail.' The modern views on pyelonephritis are not stated, but the section on 'Renal Dysbiotrophy' remains. There is no section summarizing the present notions on the maintenance of fluid and electrolyte balance, nor on the diagnosis and treatment of post-operative chest complications, though a page is devoted to such remedies as nascent iodine, calcium, creosote, gold and arsenic in pulmonary tuberculosis.

Surely if this book is to retain its prestige as the leading English textbook, and to take its place with modern American ones, far more drastic revision will be necessary next time.

\section{A PAThology OF THE EYe}

By Eugene WolfF, M.B., F.R.C.S. 3rd Edition. Pp. vii +364 , with 318 illustrations, 5 in colour. London: H. K. Lewis. I95 I. 55s.

The third edition of this well-known book follows the familiar pattern of its predecessors. It is well produced and printed and the many photographs are excellent.

As is usual with later editions, there has been some increase in size, an increase only too familiar to the examination candidate who has been told to read a number of more or less standard works.

The style of writing is not very happy, which is a pity, as it seriously detracts from the pleasure of reading this book. The sentences either come in a series of short bursts like machine-gun fire, or stumble along over a series of parenthetic qualifications. The subjects of many sentences are obscured, and the pronouns tend to get out of hand, particularly the notoriously difficult 'one'.

It may be that in giving prominence to this aspect your reviewer is doing an injustice to this valuable book but, except for the zealot, pathologyco is not-let us face it - a madly exciting subject? and must, for most of us, be dispensed as elegantly as possible to make it acceptable. Then, again, all patholgists have been spoilt in the matter of English prose by the exceptionally high standard set in the 'Bible' of ophthalmology.

There is one other criticism to be made and that is of the irregularity of the treatment of different topics. One or two abstruse points are subjected to exhaustive and even acrimonious debate, while other matters get short shrift.

However, this is a book that has its place in the library of eye doctors and this edition will tend to confirm rather than to weaken it.

$$
\text { E.C.G. }
$$

\section{COLOR ATLAS OF PATHOLOGY}

Prepared under the auspices of the U.S. Naval Medical School of the National Naval Medical Center, Bethesda, Maryland

Pp. $\mathrm{xi}+546$, with $\mathrm{I}, 053$ illustrations in colour. London and New York: J. B. Lippincott. $195^{\circ}$. £7.

This is a unique book designed to give, as the foreword states, ' a comprehensive concise and realistic source of reference with reproductions in full color which would bring to the student, the clinician, the laboratory diagnostician a readily utilizable and intelligible standard of comparison as a guide in the study and interpretation of both gross and microscopic findings.'

The notable feature of this book is its quality of 